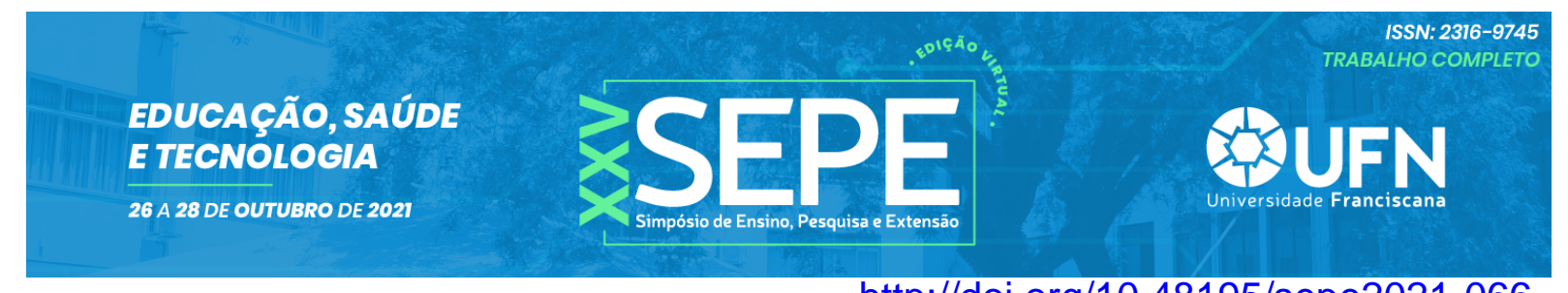

http://doi.org/10.48195/sepe2021-066

\title{
VIVÊNCIA DO ACADÊMICO DE BIOMEDICINA FRENTE À CAMPANHA DE VACINAÇÃO AO COMBATE A PANDEMIA DA COVID-19
}

\author{
Cristiano dos Santos Siqueira1; Minéia Weber Blattes ${ }^{2}$
}

\section{RESUMO}

O objetivo deste trabalho foi descrever a experiência de um acadêmico de biomedicina durante a campanha de vacinação contra a pandemia do novo Coronavírus. Trata-se de um relato de experiência do tipo descritivo com abordagem qualitativa, desenvolvido pelo acadêmico da Universidade Franciscana, localizada no Rio Grande do Sul, durante o período de março a setembro de 2021. A ação foi efetuada por intermédio da Prefeitura Municipal de Santa Maria e Secretaria Municipal de Saúde do município, coordenada por uma enfermeira da mesma Universidade junto ao Núcleo de Educação Permanente em Saúde do município. Através da vivência na campanha de vacinação contra a Covid-19 foi possível perceber que a atuação da equipe multiprofissional foi fundamental para obter ótimos resultados no enfrentamento a pandemia e, destacar o papel do biomédico no exercício frente à campanha vacinal e diagnóstico de doenças em exames laboratoriais, além da experiência adquirida quanto acadêmico de biomedicina.

Palavras-chave: Ciência da Saúde; Imunizante; SARS-CoV-2.

Eixo Temático: Atenção Integral e Promoção à Saúde.

\section{INTRODUÇÃO}

A pandemia da Covid-19 representa um dos maiores desafios de saúde global deste século. É a maior pandemia da história recente da humanidade causada pelo novo coronavírus (SARS-CoV-2). Trata-se de uma infecção respiratória aguda potencialmente grave, que possui elevada transmissibilidade entre as pessoas por meio de gotículas respiratórias ou contato com objetos e superfícies contaminadas. Poucos meses após o surto na China, em dezembro de 2019, mais de 1,5 milhão de casos foram notificados e 85.000 mortes em todo o mundo, e os desafios só aumentaram quando o vírus invisível se espalhou ainda

\footnotetext{
${ }^{1}$ Acadêmico do Curso de Biomedicina - Universidade Franciscana/UFN cristiano.siqueira@ufn.edu.br

${ }^{2}$ Orientadora. Professora do Curso de Biomedicina - Universidade Franciscana/UFN mweber@ufn.edu.br
} 
mais, números ainda maiores de casos foram esperados e mais mortes ocorreram (ANVISA, 2020).

O primeiro caso de Covid-19 no Brasil teve diagnóstico molecular confirmado no dia 26 de fevereiro pela equipe do Adolfo Lutz. Trata-se de um paciente infectado na Itália, possivelmente entre os dias 9 e 21 deste mesmo mês. O sequenciamento do genoma viral foi conduzido por uma equipe brasileira coordenada por Claudio Tavares Sacchi, responsável pelo Laboratório Estratégico do Instituto Adolfo Lutz (LEIAL), e Jaqueline Goes de Jesus, biomédica, pós-doutoranda na Faculdade de Medicina da USP e bolsista da FAPESP (FAPESQ, 2021).

No Brasil, o novo coronavírus trouxe para a população novas rotinas e novas perspectivas no âmbito da assistência à saúde. O vírus se espalhou pelo país, em parte pela demora em testar os suspeitos, dar os resultados e isolá-los, e pela falha na proteção dos profissionais de saúde, o que gerou disseminação também a partir dos serviços de saúde. Além disso, muitos contactantes não procuram os serviços de saúde, pois desenvolvem doença leve, o que dificultou a identificação de casos e controle da pandemia Covid-19 e a disseminação do vírus (SILVA, 2020). Por estes fatos, até o mês setembro de 2021, o Brasil acumula mais de 20.000.000 de casos confirmados de Covid-19 (BRASIL, 2021a).

Nesse contexto, este trabalho relata a experiência e atividades realizadas pelo acadêmico de biomedicina, inserido em uma equipe multiprofissional de voluntários, nas campanhas de vacinação contra a Covid-19.

\section{METODOLOGIA}

Este trabalho consistiu em um relato de experiência do tipo descritivo com abordagem qualitativa, vivenciado pelo autor, no período de março a setembro de 2021. Este relato versa sobre a experiência do acadêmico de biomedicina durante o período de imunizações contra o vírus SARS-CoV-2, em um município do interior do Rio Grande do Sul. A ação foi efetuada por intermédio da Secretaria Municipal de Saúde do município e coordenada por uma enfermeira da mesma instituição do autor. A discussão dessa vivência ocorre a partir de um olhar qualitativo, que abordou problemáticas a partir de métodos descritivos e observacionais. $O$ relato de 
experiência é uma ferramenta de pesquisa descritiva, que apresenta uma reflexão em âmbito profissional e de interesse da comunidade científica.

\section{RESULTADOS E DISCUSSÕES}

O Rio Grande do Sul e o mundo enfrentaram grandes desafios impostos por esta pandemia, desafios estes que vêm sendo anunciados pelas mídias sociais desde seu início. Com isso foi oportunizado o tempo necessário para a devida preparação das estruturas físicas e estratégicas, bem como proporcionar treinamentos aos profissionais voluntários que iriam trabalhar na linha de frente nas vacinações (RODRIGUES; SILVA, 2020).

Entre as medidas indicadas pelo Ministério da Saúde (MS) para o controle da pandemia, estão as não farmacológicas, como distanciamento social, etiqueta respiratória e de higienização das mãos, uso de máscaras, limpeza e desinfeção de ambientes e isolamento de casos suspeitos e confirmados conforme orientações médicas. Estas medidas devem ser utilizadas de forma integrada, a fim de controlar a transmissão da Covid-19, permitindo também a retomada gradual das atividades desenvolvidas pelos vários setores e o retorno seguro do convívio social (BRASIL, 2020).

Dentre as intervenções para conter os impactos da pandemia no Brasil, foram propostas do MS a aceleração no desenvolvimento de vacinas, intervenções terapêuticas e testes diagnósticos (DOMINGUES, 2021). O MS apresentou como medida de combate à doença o Centro de Operações de Emergências em Saúde Pública para o novo Coronavírus (COE - nCoV), estratégia para o Plano Nacional de Operacionalização da Vacinação contra a Covid-19, definido como Emergência de Saúde Pública de Importância Internacional (BRASIL, 2021b).

A equipe de cientistas que publicou a sequência do vírus em dois dias, o que proporcionou candidatos em fase pré-clínica e em fase de pesquisa clínica para a elaboração das vacinas da Covid-19 no mundo. Duas foram selecionadas como aptas à introdução na rede pública de saúde do Plano Nacional de Imunização, sendo estas as vacinas CoronaVac, proveniente da Farmacêutica Sinovac/Butantan, e a AstraZeneca, produzida pela Universidade de Oxford em parceria com a Fundação Oswaldo Cruz (Fiocruz) e com o Instituto Serum da Índia, constituídas 
respectivamente pelo vírus inativado SARS-CoV-2 e o adenovírus recombinante (BRASIL, 2021b). Atualmente já são quatro tipos diferentes de vacinas contra a Covid-19 sendo aplicadas na população brasileira: a Comirnaty (Pfizer/BioNTech), a Coronavac (Butantan/Sinovac), a Covishield (AstraZeneca/Oxford) e a vacina da Janssen. Esta última, além da vantagem de ser aplicada em dose única, dados preliminares indicam que ela pode ser eficaz em deter as variantes do Coronavírus, inclusive a Delta (JERALD SADOFF et al., 2021).

A vivência acadêmica em um momento pandêmico torna-se fundamental no processo formativo tendo em vista que possibilita o planejamento e estratégias de atuação no que se refere a promoção da saúde e prevenção do agravo. Ainda, proporciona a visualização e o trabalho em prol da ciência reiterando a importância das campanhas de imunização.

Durante a atuação nas campanhas de vacinação, foi ampliado o aprendizado acerca da atuação do biomédico em diversas áreas do conhecimento cientifico, conhecimentos relacionados aos imunobiológicos e inserção do profissional na saúde coletiva como um todo, assim como, compreender a importância dos registros nos sistemas de informações em saúde do SUS, sendo estes, parte integrante do processo de assistência da biomedicina.

Quando iniciou a vacinação no município, devido ao grande número de pessoas a serem vacinadas na pandemia, surgiu a necessidade de criar grupos de voluntários da saúde para atuarem na linha de frente nas ações de vacinação. Uma das instituições de ensino voluntarias foi a Universidade Franciscana, na cidade de Santa Maria, RS, que disponibilizou mais de 300 acadêmicos da área da saúde junto aos seus professores para atuarem nas vacinações e no diagnóstico molecular da Covid-19. A campanha de imunização contra a Covid-19 ocorreu em todas Unidades Básicas de Saúde da cidade e estabelecimentos comerciais de grande porte, em datas e horários pré-estabelecidos durante a semana, sempre seguido o calendário Nacional de vacinação.

Nas campanhas de vacinação, o Núcleo de Educação Permanente em Saúde do município organizou e dividiu os setores para a população que acudia os locais de carro ou a pé. Em seguida ocorreu a divisão dos profissionais de saúde e os 
apoiadores, em conjunto com os acadêmicos de biomedicina, enfermagem, medicina, nutrição, fisioterapia, odontologia e demais áreas da saúde do município. Foram divididas funções de atendimento entre a triagem/orientação, preenchimentos dos dados, quantitativos de pessoas vacinadas e os profissionais de saúde responsáveis pela administração da vacina.

Durante a pandemia da Covid-19, o MS e os conselhos representativos de classe autorizaram a utilização da tecnologia da informação e comunicação para a realização de orientação, monitoramento e encaminhamentos à distância para usuários, bem como a troca de informações e opiniões entre os profissionais a respeito dos casos de usuários acompanhados (CONASEMS; CONASS, 2020).

Além disso, como acadêmico de biomedicina, através das campanhas de vacinação, observou-se a falta de ações preventivas para conscientizar e informar a sociedade como um todo do que é realmente o controle epidemiológico, através de materiais de apoio e redes sociais, assim como o diálogo em escolas e universidades. O papel do profissional da saúde é imprescindível na capacitação de demais áreas e equipes. Do mesmo modo, observou que o biomédico é um profissional qualificado para a formação permanente, buscando desenvolver competências individuais e coletivas em seu processo de trabalho em saúde, atuando nas ações de informação das características dos imunobiológicos ou das doenças, seus eventos adversos, suas indicações, a fim de aperfeiçoar o trabalho e proporcionar maior qualidade na saúde da população.

Foi importantíssimo o nível de aproveitamento do acadêmico de biomedicina frente à realidade da pandemia da Covid-19, principalmente no que diz respeito a oportunidade de somar conhecimentos de forma positiva para a população, além de contribuir com a experiência adquirida em relação aos conhecimentos sobre a doença do novo Coronavírus, no diagnóstico e no desenvolvimento e aperfeiçoamento dos conhecimentos teóricos e práticos dentro de um laboratório de pesquisa cientifica. Percebeu-se a necessidade de realização de ação de educação em saúde à comunidade acerca do vírus SARS-CoV-2, a funcionalidade do sistema de saúde pública e o conhecimento sobre a vacinação, sendo pontos cruciais para 
EDUCAÇÃO, SAÚDE

ETECNOLOGIA

26 A 28 DE OUTUBRO DE 2021

promover a saúde coletiva de forma efetiva à sociedade e maior adesão à campanha vacinal.

\section{CONCLUSÃO}

A vacinação é a maneira mais eficaz de se evitar diversas doenças, como a varíola que foi erradicada por esse meio, a poliomielite que causa paralisia infantil, o sarampo, tuberculose, rubéola, gripe, hepatite B e febre amarela, entre outras. Assim como o saneamento básico, a vacina é o segundo fator de maior proteção da saúde humana. É um assunto de saúde pública que vem crescendo muito durante todos esses anos. As vacinas disponibilizadas atualmente são seguras e eficazes contra o SARS-CoV-2, desenvolvidas após anos de estudos científicos e atuam na prevenção, induzindo a formação de anticorpos por parte do sistema imunológico. Assim, são capazes de reduzir a possibilidade de infecção.

Vivenciando a campanha de vacinação contra a Covid-19, foi possível perceber a importância da vacinação para a sociedade em relação à prevenção de doenças e consequentemente a redução da morbimortalidade, principalmente em uma pandemia. Foi possível entender as normas de vacinação, como se organiza uma equipe na ocasião de uma campanha vacinal, especialmente a experiência do atendimento à população de diferentes culturas.

De forma significativa posso dizer que a participação na campanha de vacinação foi fundamental para o desenvolvimento e o aperfeiçoamento dos conhecimentos teóricos e práticos na formação como biomédico. Com isso, a presente experiência vivenciada durante a campanha de vacinação no município de Santa Maria no enfrentamento ao novo Coronavírus reitera a preocupação e a necessidade da realização de ações de educação em saúde à comunidade acerca do vírus SARS-CoV-2, a funcionalidade do sistema de saúde pública e o conhecimento sobre a vacinação, sendo pontos cruciais para promover a saúde de forma efetiva à sociedade como um todo. 


\section{REFERÊNCIAS}

AGÊNCIA NACIONAL DE VIGILÂNCIA SANITÁRIA (ANVISA). Nota técnica No 04/2020. Orientações para serviços de saúde: medidas de prevenção e controle que devem ser adotadas durante a assistência aos casos suspeitos ou confirmados de infecção pelo novo coronavírus (SARS-CoV-2). 2020. Disponível em: https://portaldeboaspraticas.iff.fiocruz.br/atencao-recem-nascido/covid-19orientacoes-da-anvisa-para-servicos-desaude/. Acesso em: 04 de setembro de 2021.

BRASIL. Ministério da saúde. CORONAVÍRUS/BRASIL. Secretarias Estaduais de Saúde. Disponível em: https://covid.saude.gov.br/. Acesso em: 06 de setembro de 2021. $2021 a$.

BRASIL. Ministério da Saúde. Guia de Vigilância Epidemiológica. Disponível em: https://portalarquivos.saude.gov.br/images/af gvs coronavirus 6ago20 ajustesfinais-2.pdf. Acesso em 12 de setembro de 2021. 2020.

BRASIL. Ministério da Saúde. Plano nacional de operacionalização da vacinação contra a Covid-19. Disponível em: https://www.gov.br/saude/ptbr/media/pdf/2021/janeiro/23/segundo-informe-tecnico-22-de-janeiro-de-2021.pdf Acesso em 06 de setembro de 2021. 2021b.

CONSELHO NACIONAL DE SECRETARIAS MUNICIPAIS DE SAÚDE (CONASEMS); CONSELHO NACIONAL DE SECRETÁRIOS DE SAÚDE (CONASS). Guia Orientador para o enfrenta- mento da pandemia Covid-19 na Rede de Atenção à Saúde. Disponível em: https://www.conasems.org.br/wpcontent/uploads/2020/05/Instrumento-Orientador-Conass-Conasems-

VERS\%C3\%830-FINAL-3.pdf. Acesso em: 12 de setembro de 2021. 2020.

DOMINGUES, C. M. A. S. Desafios para a realização da campanha de vacinação contra a COVID-19 no Brasil. Cad. Saúde Pública, v. 37, n.1, p.1-5, 2021. 
FAPESQ. Tecnologia que sequenciou coronavírus em 48 horas permitirá monitorar epidemia em tempo real. 2021. Disponível em: http://fapesq.rpp.br/noticias/tecnologia-que-sequenciou-coronavirus-em-48-horaspermitira-monitorar-epidemia-em-tempo-real Acesso em 02 de setembro de 2021.

JERALD SADOFF, M. D. et al. Safety and Efficacy of Single-Dose Ad26.COV2.S Vaccine against Covid-19. N Engl J Med, n. 384, p. 2187-2201, 2021.

RODRIGUES, N. H.; SILVA, L. G. A. Gestão da pandemia Coronavírus em um hospital: relato de experiência profissional. J. nurs. Health, v.10, n. 4, 2020.

SILVA, A. A. M. Sobre a possibilidade de interrupção da epidemia pelo coronavírus (COVID-19) com base nas melhores evidências científicas disponíveis. Rev Bras Epidemiol, n. 23, 2020. 